\title{
The Time Course of Attentional Focusing
}

\author{
Francesco Benso, Massimo Turatto, Gian Gastone Mascetti \\ and Carlo Umiltà
}

Dipartimento di Psicologia Generale, Università di Padova, Padova, Italy

In four experiments, we investigated the time course of attentional focusing. Our main aims were to estimate the time necessary for focusing to take place and the time over which focal attention can be maintained. The use of a pre-cueing procedure allowed us to estimate the time necessary for focusing, excluding the time needed for orienting. The results of the first three experiments showed that the focus of attention requires $33-66 \mathrm{msec}$ to adjust to an object in the visual field, and that active focusing cannot be maintained beyond about $500 \mathrm{msec}$. In the fourth experiment, we also investigated if focusing was as efficient at the periphery as in the centre of the visual field. The results showed that the time course of focusing is different in the periphery with respect to the centre, supporting the hypothesis of low efficiency of the attentional focus when it works outside the fovea.

\section{INTRODUCTION}

Several features of the focus of attention, including its movement, boundaries, size and shape, have been extensively explored (e.g. Egly \& Homa, 1984; Henderson, 1991; LaBerge \& Brown, 1986; Posner, 1980; Usai, Umiltà, \& Nicoletti, 1995). In particular, a number of studies have indicated that the spatial extent of the attentional focus varies in accordance with the task demands (e.g. Castiello \& Umiltà, 1990, 1992; Egeth, 1977; LaBerge 1983; Maringelli \& Umiltà, 1998; Posner, 1980). From these studies, two models have emerged.

Requests for reprints should be addressed to Carlo Umiltà, Dipartimento di Psicologia Generale, Università di Padova, Via Venezia 8, 35131 Padova, Italy.

E-mail: umilta@psico.unipd.it

We would like to express our appreciation to Andrea Facoetti and Giovanni Galfano for their help in carrying out the experiments. Thanks are also due to Sandro Bettella for his technical advice in planning the experiments. Bruce Bridgeman, Claus Bundesen and an anonymous reviewer provided very helpful comments on a previous draft of the manuscript. This research was supported by grants from CNR and MURST to G.G.M. and C.U. 
The spotlight metaphor (Posner, 1980) states that the focus works like a beam of light with a definite size, and focal attention shifts from one location to another in analogue fashion by following a continuous trajectory. Based on this model, Jonides (1983) proposed that attentional resources could be deployed in two operational modes: distributed or parallel versus focal or serial. The zoom lens metaphor (Eriksen \& St. James, 1986; Eriksen \& Yeh, 1985) states that the size of the focus changes and, consequently, the concentration of attentional resources can be modified. It explicitly predicts the existence of an inverse relation between extent of the focus and efficiency of processing within its borders. $^{1}$

Eriksen and St. James (1986) formulated three important questions: Is the size of the focus variable? Is there a relation between the size of the focus and processing speed? Are the boundaries of the focus sharp or do attentional resources fall off gradually?

Eriksen and St. James (1986), Castiello and Umiltà (1990, 1992) and Henderson (1991), among others, have provided answers to the first two questions. It is now widely accepted that the focus of attention can vary from a narrow area of less than $1^{\circ}$ to an area that covers the entire visual field. Castiello and Umiltà (1990; also see Maringelli \& Umiltà, 1998) showed that efficiency of processing was higher inside a small focus than inside a larger one, as the zoom lens metaphor predicts. In addition, Castiello and Umiltà $(1990,1992)$ reported that the size of the attentional focus did not change when the interval between cue and stimulus (stimulus onset asynchrony, SOA) was around $40-50 \mathrm{msec}$, whereas it changed with a longer SOA $(500 \mathrm{msec})$. More recently, Maringelli and Umiltà (1998) showed that an SOA of $100 \mathrm{msec}$ was long enough for the attentional focus to change.

The main aim of the present study was to investigate the time course of the process of attentional focusing. In particular, we wished to answer two questions. The first concerned the point in time when focusing begins - that is, the latency required for a change in the size of the focus to occur. The second question concerned how long focusing can be maintained once it has taken place. A secondary aim of the study was to explore if focusing is as efficient at the periphery as it is at the centre of the visual field.

\footnotetext{
${ }^{1}$ As pointed out by Bruce Bridgeman, the spotlight and the zoom lens metaphors are in fact much older. For example, Wundt (1903, p. 334; translation by Bruce Bridgeman) wrote: "One can turn the inner point of sight successively to the various parts of the inner field of view. At the same time one can narrow it or broaden it, unlike the point of sight of the external eye, whereby its brightness alternately increases and decreases. Strictly speaking it is thus not a point, but a field of somewhat variable extent".
} 
A single-item detection task was used, even though we were aware of the criticism formulated by Eriksen and St. James (1986) about this kind of task. As part of their "optimal attention allocation" principle, they stated that "a briefly exposed stimulus requiring detection may be quite insensitive to the degree of concentration of attentional resources" (Eriksen \& St. James, 1986, p. 228). In their view, recognition or discrimination tasks are preferable because they require more attentional resources. Accordingly, several studies have used recognition tasks (Egeth, 1977; Eriksen \& St. James, 1986; Jonides, 1983; LaBerge, 1988; LaBerge \& Brown, 1986).

There are, however, important arguments against the use of recognition or discrimination tasks for studying the deployment of the focus of attention. In these tasks, besides visual attention, other processes like "expectation" (categorisation of the stimulus) and "intention" (selection of the correct response) are involved (e.g. Van der Heijden, 1992).

To provide a better explanation of this concept, we refer to Von Helmholtz's and James's different views of attention. According to Von Helmholtz (1894), attention is a kind of "force" or "inner activity" that can be moved in some region of the visual field to enhance perception in that region. Therefore, attention is concerned with a region in space. The appropriate terms are "position" and "spatial location". James's (1890) view of attention is concerned more with "expectant attention" or selective attention. He used terms like "anticipatory thinking", "ideational preparation" and "anticipatory imagination" to describe his concept of attention. In addition, another important factor-preparation to react-is involved in performing an attentional task that requires the subject to discriminate between two targets by reacting in two different ways. This aspect concentrates on the implementation of the correct motor program (Rogers \& Monsell, 1995), and was first taken into consideration by Gibson (1941), who called it "intention". As Van der Heijden (1992, p. 55) stated: "in nearly all experimental tasks more attentional factors ... have to be distinguished: one process concerned with 'the where' (i.e., controlling the source of stimuli to be responded to), a second concerned with 'the what' (i.e., controlling what aspect of the stimulus is of importance), and a third concerned with 'what to do' (i.e., controlling whether, and if so, how to react)".

If, as we believe, focusing is one of the basic features of attention, like orienting in space, it should occur before other factors, like "expectation" and "intention". Therefore, a study that is exclusively concerned with the control of the focus of attention should tap the focusing process only, by excluding higher stages of information processing. 
Having as a reference the zoom lens metaphor, in the present study we assume that the inverse relation between reaction time (RT) and the size of the cue indexes the control of the attentional focus. Thus, effective focusing can be assumed to have occurred when RT to the stimulus inside the smaller cue is faster than inside the larger cue.

\section{EXPERIMENT 1}

The task consisted in performing a manual response (a keypress) when a command stimulus (a white dot) was presented inside a circle of variable size. Prior to the cue, a small green dot (the pre-cue) was briefly flashed at a random position in the visual field. The use of the pre-cue was motivated by the fact that we were exclusively interested in measuring the time required for the focusing process. Therefore, it was necessary to eliminate from the response latency the time needed to move attention towards the cue. When the SOA between the cue and the stimulus is very brief, a movement of attention towards the cue might still be in progress when the stimulus is presented. In this study, the pre-cue signalled the position where the cue was about to appear and thus allowed the subject to shift his or her eyes and attention to that position in advance. Therefore, the only operation the subjects had to perform after cue presentation was to change the size of the focus in accordance with the information provided by the cue (i.e. the size of the circle). Different SOAs between the cue and the imperative stimulus were used to investigate the time course of the focusing process.

\section{Methods}

Subjects. Thirty-four students (17 males, 17 females) attending the University of Padova took part in the experiment. All of them were righthanded and had normal or corrected-to-normal vision. They were unaware of the purpose of the experiment.

Apparatus and Procedure. The experiment took place in a dimly lit room. The subjects sat in front of a 19-inch monitor with their head positioned on a headrest, so that the distance between their eyes and the screen was about $40 \mathrm{~cm}$. The pre-cue, cue and imperative stimuli were provided by a Digital Venturis 575 personal computer. They had a luminance of $24 \mathrm{~cd} / \mathrm{m}^{2}$, whereas the luminance of the screen was $0.5 \mathrm{~cd} / \mathrm{m}^{2}$. The pre-cue and the imperative stimuli were green and white dots, respectively, of $0.5^{\circ}$ of visual angle. The cue was a white circle of $2.5^{\circ}$ or $7.5^{\circ}$. 
At the beginning of the trial, the pre-cue (the green dot) was flashed on the screen for $250 \mathrm{msec}$, accompanied by a $2000 \mathrm{~Hz}$ tone. Its spatial position changed at random from one trial to the next. Then, the pre-cue disappeared and, after an interval of $150 \mathrm{msec}$, the cue (the white circle) was presented with its centre at the same location on the screen as the pre-cue. After a variable SOA, the imperative stimulus (the white dot) was flashed at the centre of the cue for $200 \mathrm{msec}$. The SOAs were: 33, 66, 134, 184, 268, 335, 402, 469, 536 and $704 \mathrm{msec}$. Small and large cues, as well as SOAs, were presented in a random sequence. ${ }^{2}$

At stimulus onset, the subjects had to press the space-bar as fast as possible and their RT was recorded by the computer. The maximum time allowed for the response was $1 \mathrm{sec}$. Catch trials, consisting of the presentation of the cue but not of the stimulus, were presented interspersed with normal trials. On catch trials, the subjects did not have to respond.

The experimental session consisted of 184 trials, divided into two blocks of 92 trials each. The trials were distributed as follows: 40 trials with the small cue (4 for each SOA), 40 with the large cue (4 for each SOA) and 12 catch trials ( $13 \%$ of total trials).

\section{Results}

For each type of trial, RTs more than 2.5 standard deviations from the mean were eliminated prior to formal data analysis. Errors and responses on catch trials were fewer than $4 \%$ and were not analysed. Reaction times were entered into a two-way analysis of variance for repeated measures, with the factors size of the cue $\left(2.5^{\circ}\right.$ vs $\left.7.5^{\circ}\right)$ and SOA.

Both main effects were significant [size: $F(1,33)=41.153, P<0.001$; SOA: $F(9,297)=54.434, P<0.001]$ Reaction time was shorter with the small cue than with the large cue (309 vs $317 \mathrm{msec}$, respectively) and depended on the SOA. The interaction between the two factors was also significant $[F(9,297)=2.310, P<0.05]$. Newman-Keuls post-hoc tests were applied to the data, comparing the RTs for the two cue sizes at each SOA. The results were as follows: SOA $33 \mathrm{msec}$, NS; SOA $66 \mathrm{msec}$, $P<0.05$; SOA $134 \mathrm{msec}$, NS; SOA $184 \mathrm{msec}, P<0.05$; SOA $268 \mathrm{msec}$, $P<0.05$; SOA $335 \mathrm{msec}, P<0.05$; SOA $402 \mathrm{msec}, P<0.05$; SOA 469 msec, $P<0.05$; SOA $536 \mathrm{msec}$, NS; SOA $704 \mathrm{msec}$, NS. The curves describing the relation between SOA and RT for the two cue sizes are shown in Fig. 1.

\footnotetext{
${ }^{2}$ Because the stimuli were shown at $60 \mathrm{~Hz}$ on a raster-scanner monitor, their duration was overestimated by about $10 \mathrm{msec}$. However, the duration of the SOAs was as reported in the text (see Bridgeman, submitted).
} 


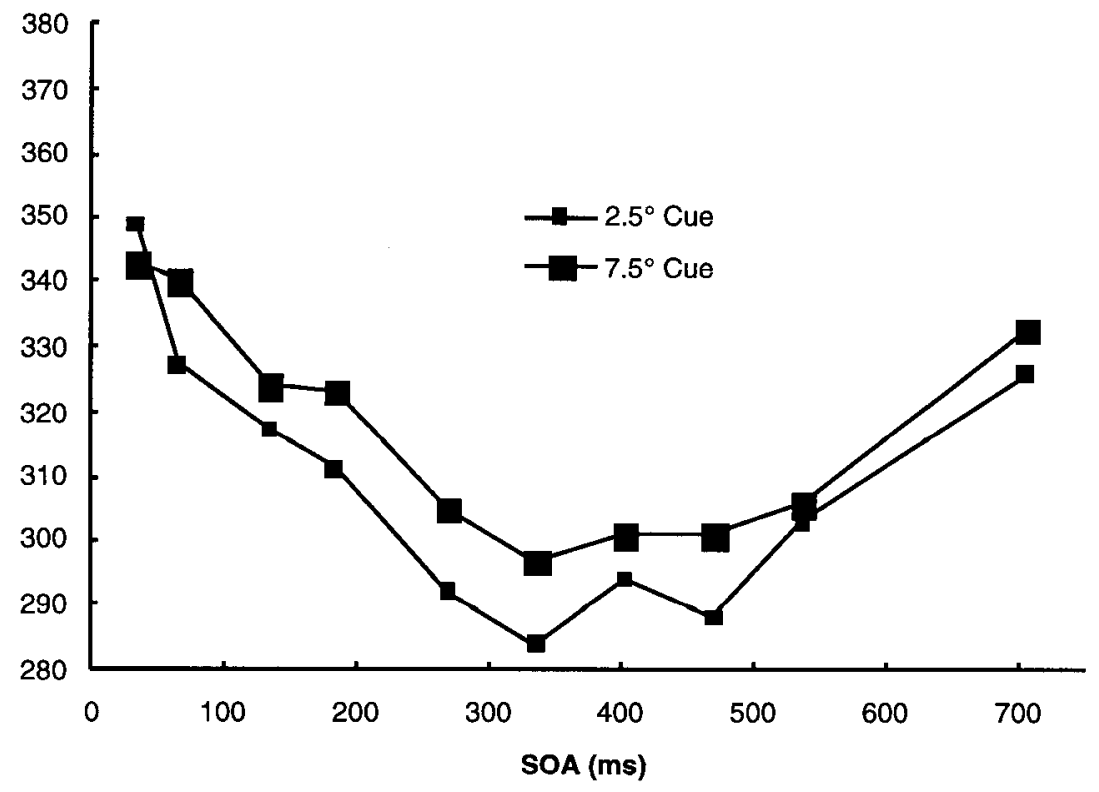

FIG. 1. Mean reaction time (RT) as a function of SOA and cue size in Experiment 1, showing that the focus of attention requires between 33 and $66 \mathrm{msec}$ to fit the shape of the cue. Active focusing can be maintained until about $500 \mathrm{msec}$; it fades out at about $700 \mathrm{msec}$.

\section{Discussion}

The results confirmed the inverse relation between size of the cue and speed of processing. Because this inverse relation is assumed to index control of the attentional focus, it can be concluded that, in Experiment 1 , control of the attentional focus did occur. On average, the difference in $\mathrm{RT}$ between the small cue and the large cue was about $10 \mathrm{msec}$. It is worth noting that the effect of cue size was probably underestimated. This is because processing of the stimulus is slowed down by the border of the cue, which is closer when the cue is small (for a discussion, see Usai et al., 1995).

In accordance with previous studies (e.g. Castiello \& Umiltà, 1990, 1992; Maringelli \& Umiltà, 1998), the present results showed that the focus of attention requires a certain time to adjust to an object in the visual field. In addition, the results provide information about the time course of the focusing operation. In particular, they allow us to estimate the time needed to begin the focusing operation and how long a given focus size can be maintained. 
The minimum amount of time needed to adapt the size of the attentional focus to the size of the cue was 33-66 msec. Between 66 and 469 $\mathrm{msec}$, the size of the focus remained unchanged, whereas after $704 \mathrm{msec}$ it no longer matched the size of the cue. The non-significance at a SOA of $134 \mathrm{msec}$ was probably due to a Type II error. The lack of focused attention at the shortest SOA was probably a result of the time interval being too short for the process to be completed. Considering that the focusing operation was not necessary to perform the task, it is reasonable to assume that, at the longest SOA, attention shifted from a focal mode to a more diffuse mode.

The inverse relation between the size of the focus and efficiency of processing in the present experiment does not support the principle of "optimal attention allocation" formulated by Eriksen and St. James (1986). The cue size effect was obtained using a single-item detection task, as previously shown by Castiello and Umiltà $(1990,1992)$ and by Maringelli and Umiltà (1998). Thus, it appears that attentional resources are allocated in a flexible way, even in the absence of higher-level processes, such as stimulus categorisation and response selection.

\section{EXPERIMENT 2}

In Experiment 1, the only function of the pre-cue was to signal the position on the screen where the cue was about to appear, allowing the subject to shift his or her eyes and attention to that position before the cue was presented. Even though the pre-cue did not provide advance information about the size of the cue, one might argue that movement to the centre of the cue was less accurate when the cue was large than when it was small. That in turn caused the R T difference between the two cue sizes. Therefore, we conducted a control experiment, in which the pre-cue always signalled the centre of the screen. In this way, no preliminary eye movement was necessary and no doubt the subject was fixating the centre of the cue when it appeared. Thus, the cue-size effect would not be attributable to eye movements.

\section{Methods}

Subjects. Ten students ( 5 males, 5 females) attending the University of Padova took part in the experiment. All of them were right-handed and had normal or corrected-to-normal vision. They were unaware of the purpose of the experiment.

Apparatus and Procedure. The apparatus and procedure were as in Experiment 1, except that the pre-cue did not change position randomly, 
but was always presented at the centre of the screen. Because Experiment 1 had already provided an estimate of the time course of focusing, in Experiment 2, which was basically a control experiment, only four SOAs were used: 33, 200, 402 and $704 \mathrm{msec}$.

The experimental session consisted of 160 trials, divided into two blocks of 80 trials each. The trials were distributed as follows: 32 trials with the small cue ( 8 for each SOA), 32 trials with the large cue ( 8 for each SOA) and 16 catch trials (about $20 \%$ of total trials).

\section{Results}

For each type of trial, RTs more than 2.5 standard deviations from the mean were eliminated prior to formal data analysis. Errors and responses on catch trials were fewer than $3 \%$ and were not analysed. Reaction times were entered into a two-way analysis of variance for repeated measures, with the factors size of the cue $\left(2.5^{\circ} v s 7.5^{\circ}\right)$ and SOA.

Both main effects were significant [size: $F(1,9)=6.301, P<0.03$; SOA: $F(3,27)=59.647, P<0.001]$ Again, RT was shorter with the small cue than with the large cue (295 vs $303 \mathrm{msec}$, respectively) and was dependent on the SOA. The interaction between the two factors was also significant $[F(3,27)=4.935, P<0.007]$ As in Experiment 1 , NewmanKeuls post-hoc tests were applied to the data, comparing R Ts for the two cue sizes at each SOA. The results were as follows: SOA $33 \mathrm{msec}$, NS; SOA $200 \mathrm{msec}, P<0.05$; SOA $402 \mathrm{msec}, P<0.05$; SOA $704 \mathrm{msec}$, NS. The curves describing the relation between SOA and RT for the two cue sizes are shown in Fig. 2.

\section{Discussion}

The results of Experiment 2 confirmed those of Experiment 1, showing that eye movements had not caused the R T difference between the two cue sizes in Experiment 1. Also, in Experiment 2, we again found that focusing was not present until about $30 \mathrm{msec}$ and then disappeared after about $500 \mathrm{msec}$. In brief, the findings of Experiment 1 were fully replicated, despite the fact that eye movements had been eliminated.

\section{EXPERIMENT 3}

Experiments 1 and 2 provided evidence that the focus of attention, once fitted to a visual object, cannot be actively maintained beyond about 500 


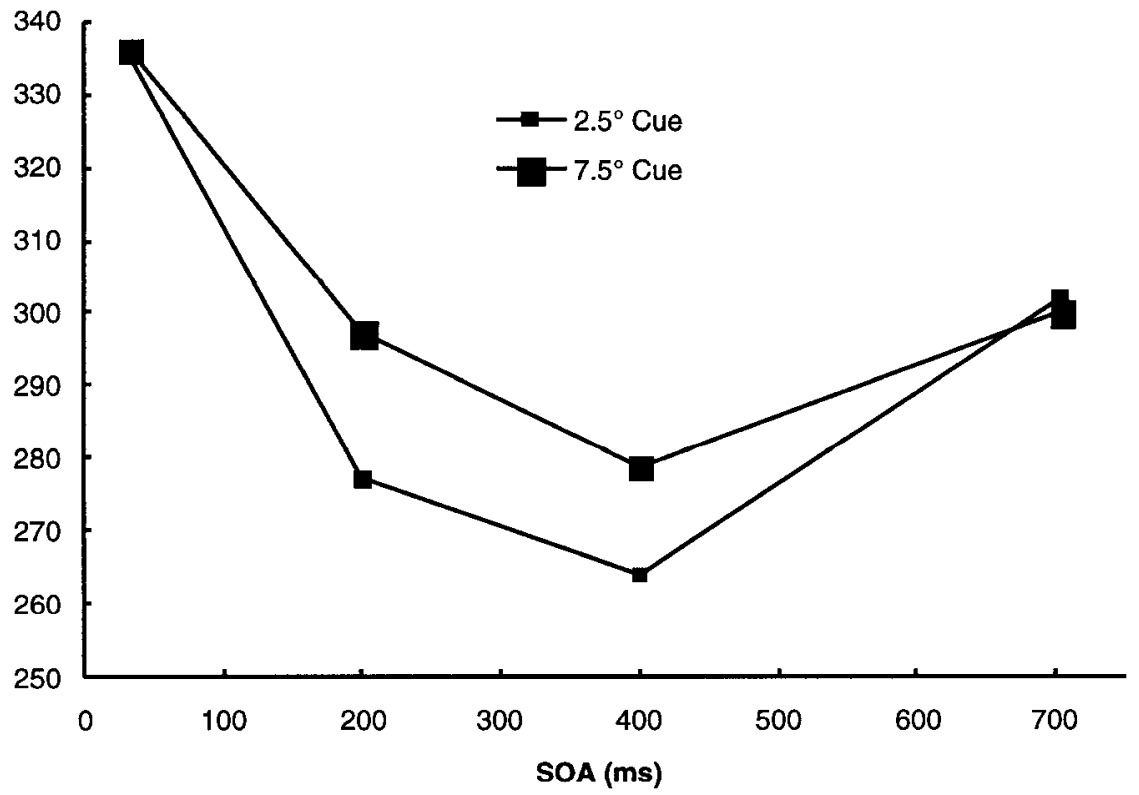

FIG. 2. Mean reaction time (RT) as a function of SOA and cue size in Experiment 2. The pattern of results is the same as in Experiment 1, showing that presenting the pre-cue at fixation did not produce different effects.

msec. However, one might argue that the subjects were not given enough incentive to maintain the focus. This could be particularly true in the case of the large cue, where there was perhaps a tendency to narrow the focus on the centre of the cue. That would explain the lack of the cue-size effect after about $500 \mathrm{msec}$. Experiment 3 explored this possibility. The critical experimental manipulation was that, inside the large cue, the stimulus could appear either at the centre or $6^{\circ}$ from the centre. We reasoned that, in this way, the subjects would be induced to maintain a large focus for as long as possible.

\section{Methods}

Subjects. Sixteen students ( 8 males, 8 females) attending the University of Padova participated in the experiment. All of them were righthanded and had normal or corrected-to-normal vision. They were all unaware of the purpose of the experiment.

Apparatus and Procedure. The apparatus and procedure were as in Experiment 1, except for the number of SOAs and the position of the 
stimulus inside the large cue. As in Experiment 2, we used only four SOAs: 33, 200, 402 and $704 \mathrm{msec}$.

The experimental session consisted of 176 trials, divided into two blocks of 88 trials each. The trials were distributed as follows: 24 trials with the small cue (6 for each SOA), 24 trials with the large cue and the stimulus at its centre ( 6 for each SOA), 24 trials with the large cue and the stimulus $6^{\circ}$ from its centre ( 6 for each SOA) and 16 catch trials (about $16 \%$ of total trials). When the stimulus was presented $6^{\circ}$ from the centre of the large cue, it could appear, with equal probability, above, below, to the right or to the left.

\section{Results}

For each type of trial, RTs more than 2.5 standard deviations from the mean were eliminated prior to formal data analysis. Errors and responses on catch trials were fewer than $4 \%$ and were not analysed. Reaction times were entered into a two-way analysis of variance for repeated measures, with the factors size of the cue $\left(2.5^{\circ}\right.$ vs $\left.7.5^{\circ}\right)$ and SOA.

Both main effects were significant [size: $F(1,15)=7.466, P<0.015$; SOA: $F(3,45)=59.647, P<0.001]$ Reaction time was shorter with the small cue than with the large cue (319 vs $326 \mathrm{msec}$, respectively) and was dependent on the SOA. The interaction between the two factors was also significant $[F(3,45)=4.231, P<0.01]$. Newman-Keuls post-hoc tests were applied to the data, comparing the RTs for the two cue sizes at each SOA. The results were as follows: SOA $33 \mathrm{msec}$, NS; SOA 200 msec, $P<0.05$; SOA $402 \mathrm{msec}, P<0.05$; SOA $704 \mathrm{msec}$, NS. The curves describing the relation between SOA and RT for the cue sizes are shown in Fig. 3.

\section{Discussion}

The aim of this experiment was to test our claim that, after about 500 msec, the focus of attention cannot be actively maintained. Based on the results of Experiments 1 and 2, an alternative explanation was tenable for why the cue-size effect disappeared after about $500 \mathrm{msec}$. Considering that the stimulus always appeared at the centre of the cue, and thus a large attentional focus was not necessary, it would seem likely that in Experiments 1 and 2 the subjects narrowed the attentional focus when the SOA became too long. This alternative explanation was ruled out by Experiment 3, in which the stimulus could appear away from the centre of the large cue, thus rendering it beneficial to maintain a large attentional focus. Despite that, the cue-size effect again disappeared after about $500 \mathrm{msec}$. 


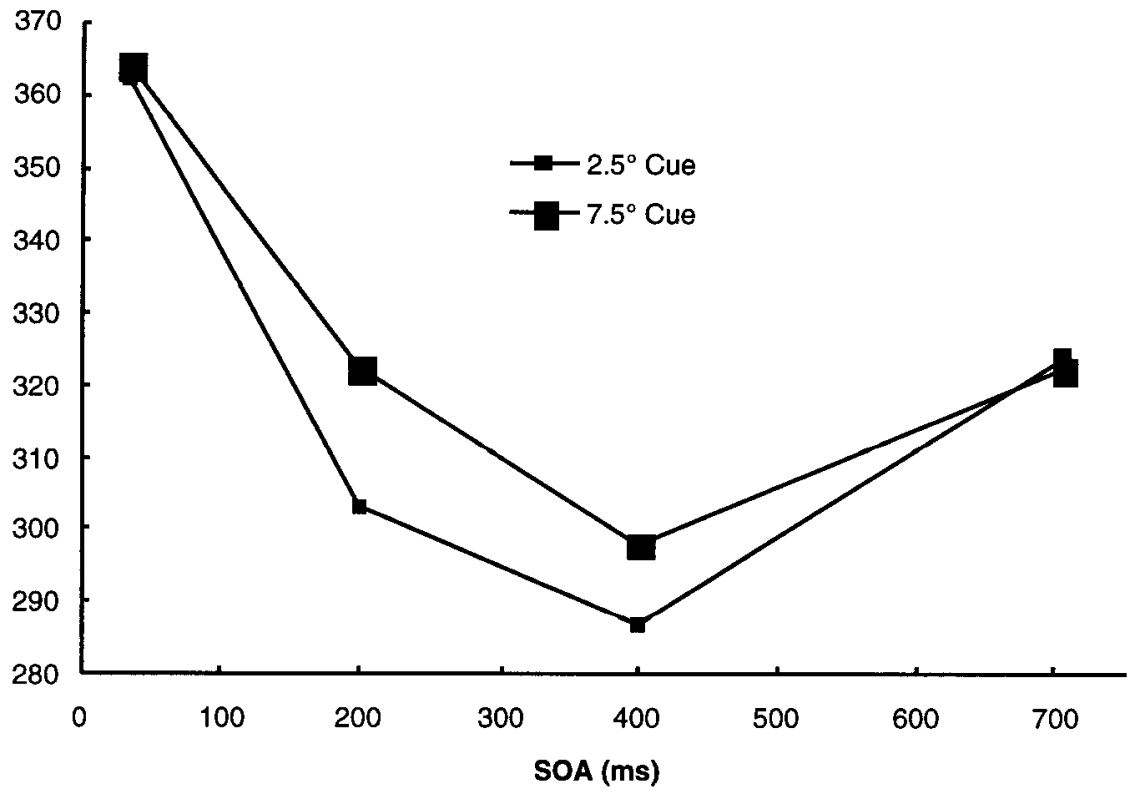

FIG. 3. Mean reaction time (RT) as a function of SOA and cue size in Experiment 3. The pattern of results is the same as in Experiment 1, showing that presenting the stimulus $6^{\circ}$ from the centre of the large cue did not produce different effects.

\section{EXPERIMENT 4}

There are reasons to assume that the efficiency of the focusing process is lower at the periphery than at the centre of the visual field (Eriksen \& St. James, 1986). It is well known that, outside the central part of the visual field, the resolution of details is poor, resulting in a low quality of the images perceived in that part of the field. Because gestalt properties (i.e. shape) seem to be important for attention (Duncan, 1984; Duncan \& Humphreys, 1989), we considered it of interest to study how temporal control of the attentional focus is exerted when attention is disaligned from central vision. As shown by Castiello and Umiltà (1990, 1992), focusing also occurs in the periphery, but it may work differently and/or less efficiently.

\section{Methods}

Subjects. Eighteen students ( 9 males, 9 females) attending the University of Padova served as subjects. They were all right-handed, had normal 
or corrected-to-normal vision, and were unaware of the purpose of the experiment.

Apparatus and Procedure. The pre-cue, the cues and the imperative stimulus were as in Experiment 1, except that, in the present experiment, focusing took place at the periphery of the visual field.

The experimental session consisted of 184 trials divided into two blocks of 92 trials, which were distributed as follows: 40 trials with the small cue (4 for each SOA), 40 trials with the large cue (4 for each SOA) and 12 catch trials $(13 \%$ of total trials) in which the subject was instructed not to respond.

Each trial started with the onset of the point of fixation (a small cross of about $1^{\circ}$ of visual angle) in the central part of the screen. The subjects kept their eyes on the point of fixation throughout the trial. After 400 $\mathrm{msec}$, the pre-cue appeared in a location in the visual field that ranged between $6.5^{\circ}$ and $10^{\circ}$ to the right or to the left of fixation. Cue location was randomly assigned. Then, after $150 \mathrm{msec}$, the cue was presented with its centre at the same location indicated by the pre-cue, and was followed by the imperative stimulus at variable SOAs. Also, sequences of cue size and SOA were randomly assigned. The subjects were instructed to press the space-bar in response to the stimulus and their R T was recorded.

Eye movements were monitored by a system composed of infrared ray spectacles, an amplifier and an analog-to-digital converter connected to the computer. The system could detect eye movements larger than $1^{\circ}$. When an eye movement was detected, the corresponding trial was eliminated.

\section{Results}

For each type of trial, RTs more than 2.5 standard deviations from the mean were eliminated prior to formal data analysis. Errors and responses on catch trials were fewer than $4 \%$ and were not analysed. A two-way analysis of variance for repeated measures was used to analyse R Ts, with factors size of the cue $\left(2.5^{\circ}\right.$ vs $\left.7.5^{\circ}\right)$ and $\operatorname{SOA}(33,66,134,184,268,335$, 402, 469, 536 and $704 \mathrm{msec})$.

The two main effects were significant [size: $F(1,17)=8.220, P<0.01$; SOA: $F(9,153)=34.938, P<0.001]$ Reaction time with the $2.5^{\circ}$-cue was shorter than with the $7.5^{\circ}$-cue (356 vs $363 \mathrm{msec}$, respectively). Reaction time gradually decreased and then gradually increased as a function of SOA. The interaction was not significant $[F(9,153)=0.968$, $P>0.4]$. Despite that, the results were further analysed with NewmanKeuls post-hoc tests. The values obtained for the SOAs were as follows: SOA $33 \mathrm{msec}$, NS; SOA $66 \mathrm{msec}$, NS; SOA $134 \mathrm{msec}$, NS; SOA 184 


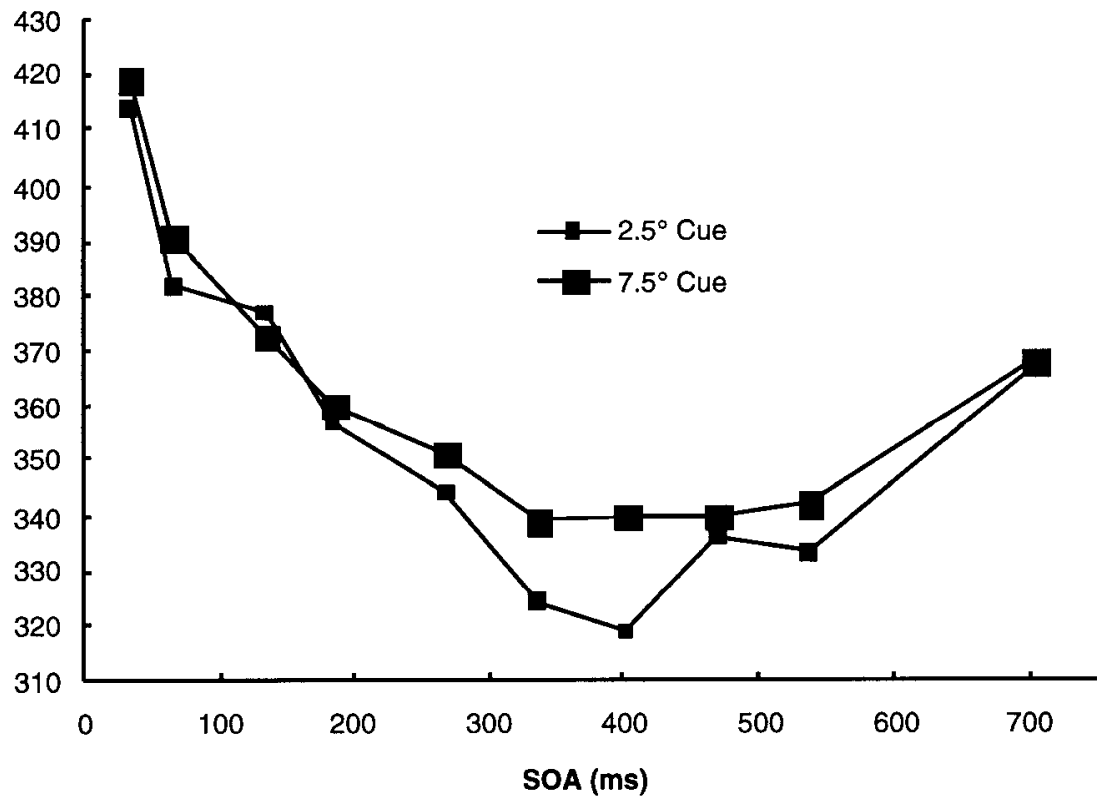

FIG. 4. Mean reaction time (RT) as a function of SOA and cue size in Experiment 4. Peripheral vision affected the time course of focusing. The cue-size effect was present at SOAs of 335 and $402 \mathrm{msec}$ only.

msec, NS; SOA $268 \mathrm{msec}$, NS; SOA $335 \mathrm{msec}, P<0.05$; SOA $402 \mathrm{msec}$, $P<0.05$; SOA $469 \mathrm{msec}$, NS; SOA $536 \mathrm{msec}$, NS; SOA $704 \mathrm{msec}$, NS. Therefore, cue size had a statistically significant effect only when the SOA was 335 or $402 \mathrm{msec}$. The curves describing the relation between SOA and $\mathrm{RT}$ for the two cue sizes are shown in Fig. 4.

\section{Discussion}

The results of Experiment 4 indicate that control of the attentional focus took place at the periphery of the visual field, but exclusively when the time interval between the cue and the imperative stimulus was between 300 and $400 \mathrm{msec}$. Castiello and Umiltà $(1990,1992)$ presented both the cue and the imperative stimulus at the periphery and reported that the cue-size effect was present at a SOA of $500 \mathrm{msec}$, that is about 100-150 msec later than in the present experiment. However, the two findings are easily reconciled if one considers that the $500 \mathrm{msec}$ SOA of Castiello and Umilta included both the time needed for focusing and the time needed for orienting attention. As mentioned above, this means that, after subtracting the time needed for orienting, the actual SOA was at least 
$100 \mathrm{msec}$ shorter. Note that Maringelli and Umiltà (1998), who presented the cue at fixation, found a cue-size effect with a $100 \mathrm{msec}$ SOA, but did not test shorter SOAs.

The results of Experiment 4 support the hypothesis of Eriksen and St. James (1986), who suggested a low level of efficiency of the focus of attention when it works outside the fovea. Duncan (1984) and Duncan and Humphreys (1989) demonstrated that the efficiency with which attention is allocated to a stimulus depends on the proper perception of its form. Thus, it is reasonable to assume that the poor resolution of details provided by the outer region of the fovea requires time to allow correct perception of the shape of the cue, therefore increasing the time needed by attention for focusing on the object.

Alternatively, the inhibition of spontaneous eye movements triggered by the onset of the cue might be considered to be a secondary task the subject had to perform simultaneously with the attentional focusing task. This secondary task might have subtracted resources from those required to focus attention, thus changing the time course of focusing.

\section{CONCLUSION}

On the basis of previous studies (e.g. Castiello \& Umiltà, 1990, 1992; Eriksen \& St. James, 1986; Eriksen \& Yeh, 1985; Maringelli \& Umiltà, 1998), we assumed the cue-size effect indexes control of the attentional focus. The experiments were planned to study the time course of the cuesize effect and, by implication, of the control of the attentional focus. The use of a single-item detection task and of a pre-cueing procedure allowed us to exclude processes different from focusing, like attention orienting, stimulus categorisation and response selection. With regard to the questions asked in the Introduction, our results provide interesting answers.

The focusing operation takes between 33 and $66 \mathrm{msec}$ to begin. A 33 msec SOA is probably too short for the process to be completed. Once a suitable size of the attentional focus is obtained, it can be maintained for up to about $500 \mathrm{msec}$, beyond which the attentional focus no longer matches the size of the cue. At SOAs longer than $500 \mathrm{msec}$, focusing disappears, perhaps because it is replaced by a diffuse attention mode.

It appears that the process of attentional focusing occurs as follows. First, there is a period during which the focus of attention is automatically triggered by the abrupt onset of the cue (see Maringelli \& Umiltà, 1998). Then there is a period during which the size of the attentional focus is actively maintained. Then attention switches to the diffuse mode. It is possible, however, that these temporal constraints apply to normal 
subjects only. There are in fact individuals who belong to special populations (e.g. schizophrenics and closed head injury patients) for whom the time course of focusing is different (Mizuno, Umiltà, \& Sartori, 1998; R oth et al., 1980).

The focusing process also occurs at the periphery of the visual field, but there the time course of the operation seems to be different. The results of Experiment 4 indicate that peripheral focusing took place exclusively at SOAs of 335 and $402 \mathrm{msec}$. The lower level of efficiency of peripheral focusing can be attributed to the low acuity and less detailed processing in the peripheral retina. It would appear that, in accordance with the proposal of Eriksen and St. James (1986), the control of focus size primarily occurs in central vision, where processing capacity is highest.

In conclusion, our results confirm that the size of the focus changes according to the spatial information provided by the cue. The inverse relation between the size of the focus and efficiency of processing was also confirmed, thus providing further support for the zoom lens metaphor of Eriksen and Yeh (1985; also see Eriksen \& St. James, 1986; Wundt, 1903), which maintains that, the smaller the focus, the more concentrated the attentional resources.

Finally, it should be noted that a single-item detection paradigm proved to be perfectly suitable for studying the temporal dynamics of focusing. Thus the suggestion of Eriksen and St. James (1986) that the characteristics of the focusing operation are best revealed by recognition or discrimination tasks was not supported.

Manuscript received March 1997

Revised manuscript received October 1997

\section{REFERENCES}

Bridgeman, B. (submitted). Misreported durations of stimuli displayed on VDT.

Castiello, U., \& Umiltà, C. (1990). Size of the attentional focus and efficiency of processing. Acta Psychologia, 73, 195-209.

Castiello, U., \& Umiltà, C. (1992). Splitting focal attention. Journal of Experimental Psychology: Human Perception and Performance, 3, 837-848.

Duncan, J. (1984). Selective attention and the organization of visual information. Journal of Experimental Psychology: General, 113, 501-507.

Duncan, J., \& Humphreys, G. (1989). Visual search and stimulus similarity. Psychological Review, 9, 433-458.

Egeth, H. (1977). Attention and preattention. In G.H. Bower (Ed.), The psychology of learning and motivation, Vol. 11, pp. 277-320. New York: Academic Press.

Egly, R., \& Homa, D. (1984). Sensitization of the visual field. Journal of Experimental Psychology: Human Perception and Performance, 10, 779-793. 
Eriksen, C.W., \& St. James, J.D. (1986). Visual attention within and around the field of focal attention: A zoom lens model. Perception and Psychophysics, 40, 225-240.

Eriksen, C.W., \& Yeh, Y.Y. (1985). Allocation of attention in the visual field. Journal of Experimental Psychology: Human Perception and Performance, 5, 583-595.

Gibson, J.J. (1941). A critical review of the concept of set in contemporary experimental psychology. Psychological Bulletin, 38, 781-817.

Henderson, J.M. (1991). Stimulus discrimination following covert attentional orienting to an exogenous cue. Journal of Experimental Psychology: Human Perception and Performance, $17,91-106$.

James, W. (1890). The principles of psychology, New York: Holt.

Jonides, J. (1983). Further toward a model of the mind's eye's movement. Bulletin of the Psychonomic Society, 21, 247-250.

LaBerge, D. (1983). Spatial extent of attention to letters and words. Journal of Experimental Psychology: Human Perception and Performance, 9, 371-379.

LaBerge, D., \& Brown, V. (1986). Variation in size of the visual field in which targets are presented: An attentional range effect. Perception and Psychophysics, 40, 188-200.

Maringelli, F., \& Umiltà, C. (1998). The control of the attentional focus. European Journal of Cognitive Psychology, 10, 225-246.

Mizuno, M., Umiltà, C., \& Sartori, G. (1998). Control of the attentional focus in chronic schizophrenics. Cortex, 34, 263-270.

Posner, M.I. (1980). Orienting of attention. Quarterly Journal of Experimental Psychology, $32 \mathrm{~A}, 2-25$.

Rogers, R.D., \& Monsell, S. (1995). Costs of predictable switch between simple cognitive tasks. Journal of Experimental Psychology: General, 124, 207-231.

Roth, W.T., Pfefferbaum, A., Horvath, T.B., Berger, P.A., \& Koppel, B.S. (1980). P3 reduction in auditory evoked potential of schizophrenics. Electroencephalography and Clinical Neurophysiolog y, 49, 497-505.

Usai, C.M., Umiltà, C., \& Nicoletti, R. (1995). Limits in controlling the focus of attention. European Journal of Cognitive Psychology, 7, 411-439.

Van der Heijden, A.C.H. (1992). Selective attention in vision. London: Routledge. Von Helmholtz, H. (1894). Handbuch der physiologischen Optik. Hamburg: L. Vos.

Wundt, W. (1903). Physiologische Psychologie, Vol. III, 5th edn. Leipzig: Engelmann. 